\title{
Nanomedicine perspective in HIV therapy: biosynthesized gold nanoparticles exhibiting enhanced anti-HIV property
}

\author{
M. R. Kamala Priya', Manickam Ashokkumar², Lucia K. Precilla², Luke Elizabeth Hanna² and Priya R. Iyer ${ }^{\text {** }}$
}

\begin{abstract}
Background: Globally, HIV/AIDS is a major public health issue. Currently, available antiretroviral therapy (ART) has a number of impediments. The need for long-term usage of antiretroviral drugs is associated with the problem of drug resistance, high cost, and other side effects. Hence, there is a constant urge for the development of novel drugs to combat the disease. The synthesis of nanoparticles is of great interest because of their reported application in diverse fields. In contrast to chemical synthesis, green synthesis is inexpensive and enviro-safe.

Results: Calophyllum inophyllum (CI) is a plant that is known to possess anti-HIV activity. Hence, this plant was exploited for the synthesis of gold nanoparticles (AuNPs) in the present study. Two parts of the plant, namely, the fruit and leaves (CIF and CIL) were used for the synthesis of nanocompounds. The two nanocompounds were tested on HIV-1 isolates at different concentrations and the $\mathrm{EC}_{50}$ values were determined. While CIF-AuNP demonstrated very good anti-HIV activity with an $\mathrm{EC}_{50}$ value of $0.09097 \mathrm{ng} / \mathrm{ml}$, CIL-AuNPs did not show significant anti-HIV activity.

Conclusions: The present study is a novel attempt to produce nanocompounds that incorporate the medicinal properties of certain plants that are known to have anti-HIV activity within nanoparticles, such that the compound possesses the attributes of a nanomaterial alongside the phytoactivity. Our results provide evidence to suggest that the CIF-AuNP can be further explored for in vivo activity. In vitro cytotoxicity of the AuNPs was checked in VERO cell lines using the MTT assay. Cytotoxicity was observed to be minimal at all the tested concentrations.
\end{abstract}

Keywords: Nanoparticles, SEM, AuNPs, UV-vis spectra, Zeta potential, Cytotoxicity, VERO cell line, Anti-HIV activity

\section{Background}

Nanotechnology is a discipline of science and engineering that has contributed significantly to the recent developments in many areas of medicine. It involves the design, engineering, and fabrication of materials at the atomic and molecular levels. The National Nanotechnology Initiative defines nanotechnology as the study of structures with sizes roughly in the range of 1-100 nm in at least one dimension, but structures that go up to

\footnotetext{
*Correspondence: brajuraj@yahoo.com

'Post Graduate and Research Department of Biotechnology, Women's

Christian College, College Road, Chennai, Tamilnadu 600006, India

Full list of author information is available at the end of the article
}

several hundred nanometers are also considered for nanotechnological applications [1].

When nanosized particles come into contact with biological systems, the nature of their interaction is critically influenced by the physicochemical properties. Many biological phenomena such as immune recognition and passage across biological barriers are governed by the size of the molecules. Drugs fabricated at the appropriate nanoscale dimension may have certain physicochemical and biological properties that confer pharmacological advantages when compared to conventional agents. Research in nanotechnology may translate into benefits for HIVinfected individuals, particularly if the challenges

\section{Springer Open}

( ) The Author(s). 2021 Open Access This article is licensed under a Creative Commons Attribution 4.0 International License, which permits use, sharing, adaptation, distribution and reproduction in any medium or format, as long as you give appropriate credit to the original author(s) and the source, provide a link to the Creative Commons licence, and indicate if changes were made. The images or other third party material in this article are included in the article's Creative Commons licence, unless indicated otherwise in a credit line to the material. If material is not included in the article's Creative Commons licence and your intended use is not permitted by statutory regulation or exceeds the permitted use, you will need to obtain permission directly from the copyright holder. To view a copy of this licence, visit http://creativecommons.org/licenses/by/4.0/. 
associated with anti-HIV treatment are addressed [2]. In a recent study, scientists developed a new cocktail-like drug delivery vehicle using biodegradable polymeric nanoparticles with encapsulated nonnucleoside reverse transcriptase inhibitor and surface-conjugated with HIV-1 fusion inhibitor, with an aim to achieve enhanced cellular uptake, improved antiviral activity, and prolonged blood circulation time [3].

The success rate of HIV treatment increases when a combination of drugs is used. Long-acting injectable formulations (LAI) can overcome the problem of low adherence to the antiretroviral regimen. Rilpivirine has been successfully developed as a nanoformulation for application as a LAI along with a non-ionic surfactant through wet milling [4]. When the resulting nanoparticles were administered as a single-dose long-acting injection, stable plasma concentration profiles were maintained that could be traced up to 3 months after intramuscular or subcutaneous administration in dogs [5].

The current treatment for HIV/AIDS includes a combination of three antiretroviral drugs, referred to as highly active antiretroviral therapy (HAART). Even though HAART has proved to be highly successful, long-term use of antiretrovirals leads to increased drug resistance due to inadequate adherence to the treatment schedule, reduced bioavailability, and offtarget side effects such as CNS, renal, and liver toxicity. These effects have urged us to look for better alternatives with lower levels of toxicity and increased half-life. Nanotechnology has helped in the development of surface modified nano-vehicles with better biodistribution at the target site [6]. To address the primary purpose of sustained-release, nanoparticles and fibers have a better advantage in retaining the activity of the incorporated active agent [7].

Calophyllum inophyllum is commonly referred to as tamanu, mastwood, or beach calophyllum. This plant has diverse medicinal properties and has been traditionally used as an antibacterial, anticancer, anti-inflammatory, antiplatelet, antipsychotic, antiviral, photoprotective, and piscicidal agent. It has been reported that $C$. inophyllum also has effective anti-HIV activity. Inophyllum $B$ and $\mathrm{P}^{10}$ were the first of the other compounds isolated from C. inophyllum. These compounds showed promising inhibition of HIV reverse transcriptase activity with $\mathrm{IC}_{50}$ values ranging between 38 and $130 \mathrm{nM}$. The inophyllums are reported to be potential nonnucleotide inhibitors. Another coumarin, costatolide, having anti-HIV activity has also been isolated [8].

Calophyllum inophyllum was previously utilized as crude extracts in the treatment and management of various ailments. In the present study, as a novel attempt, the plant extract was developed into a nano formulation and screened for its potential anti HIV properties. The plant extract was used as the reducing and stabilizing agent for the synthesis of nanoparticles. The biosynthesized nanoparticles will possess the bioactivity of the plant along with the characteristics of a nanomaterial such as enhanced workability, high surface area, and site specific activity.

With this background, the present study was aimed at the biosynthesis of gold nanoparticles using the plant extracts of Calophyllum inophyllum so as to incorporate the anti-HIV properties of the plant within the nanoparticles.

\section{Methods}

\subsection{Preparation of plant extract}

The plant specimens Calophyllum inophyllum leaves and Calophyllum inophyllum fruit used in this study were collected from our college campus, Women's Christian College, Chennai. The formal identification of the plant material used in the study was identified by Dr. G. Jeya Jothi, Taxonomist, Department of Plant Biology \& Biotechnology, Loyola College, Chennai. I would like to confirm that no voucher specimen of this material has been deposited. Five grams each of Calophyllum inophyllum leaves (CIL) and Calophyllum inophyllum fruit $(C I F)$ were washed well, taken in a conical flask and boiled for 5-10 min. The extracts were cooled and filtered through a Whatman filter paper. The filtrates were stored at $4{ }^{\circ} \mathrm{C}$ and used for further synthesis.

\subsection{Preparation of stock solution with chloroauric acid}

The stock solution was prepared using chloroauric acid, $\mathrm{AuCl}_{4}{ }^{-}$, which served as the precursor for synthesis of gold nanoparticles. Chloroaurate was dissolved in double distilled water and the $\mathrm{pH}$ of the solution was adjusted to alkaline ( $\mathrm{pH} 8)$. This was stored as stock solution and used for further synthesis [9].

\subsection{Synthesis of gold nanoparticles}

For the synthesis of gold nanoparticles (AuNPs), the $\mathrm{pH}$ of the chloroauric acid was checked and adjusted to 8 . The plant extract was added to chloroauric acid solution at room temperature. The plant extract served as the reducing and stabilizing agent and aided in the synthesis of the nanomaterial. The initial confirmation of the formation of nanoparticles was based on the distinctive change in color of chloroauric acid from pale yellow to deep wine red, as a result of the shift in the absorption spectrum of the nanoparticles [10].

\subsection{Characterization of nanoparticles using UV-visible spectrophotometer}

The bio-reduction of gold chloride in aqueous solution was monitored by periodic sampling of aliquots of the suspension. One milliliter of the sample was diluted with 
$30 \mathrm{ml}$ of double distilled water and analyzed for the presence of nanoparticles. The UV-visible spectrum of the gold nanoparticles was recorded using a Shimadzu UV 1800-UV-visible spectrophotometer operating at wavelength of 200 to $800 \mathrm{~nm}$ [11].

\subsection{SEM analysis}

The nanoparticles were diluted with MilliQ water in the ratio of 1:20 such that the concentration of the nanoparticles was reduced, so as to enable better imaging of the nanoparticles. About $10 \mu \mathrm{l}$ of sample was placed on the aluminum foil and allowed to air dry. Then scanning electron micrographs of the sample were taken using a Hitachi S-3400N, variable pressure scanning electron microscope (VP-SEM) equipped with Horiba EMAX detector, Japan, at the NCNSNT, University of Madras, Guindy, Chennai.

\subsection{EDAX—elemental analysis}

Energy dispersive X-ray analysis (EDS or EDX) is a widely used X-ray fluorescence technique that is used along with scanning electron microscopy [12]. SEM with energy dispersive X-ray analysis (EDAX) is a very useful tool for qualitative and semi-quantitative analysis of elements present in the material under analysis. The underlying working principle is that, when elements are bombarded with electrons, they give off X-rays at different frequencies characteristic to the specific element. Upon calibration, the number of X-rays given off indicates the relative amount of the specific element present in that material [13]. EDAX analysis was carried out along with SEM using a Hitachi S-3400N, variable pressure scanning electron microscope (VP-SEM) equipped with Horiba EMAX detector, Japan, at NCNSNT, University of Madras, Guindy, Chennai.

\subsection{TEM analysis}

Transmission electron microscopy (TEM) is a pivotal characterization tool for directly imaging nanomaterials. It gives a quantitative measurement of the particle size, size distribution, and morphology. TEM imaging has essentially the highest resolution as compared to other light-based imaging techniques [14]. About $10 \mu \mathrm{l}$ of the sample was placed on the TEM grid and allowed to air dry. Then transmission electron micrographs of the samples were taken using a Philips CM 200 camera, operating at voltages between 20 and $200 \mathrm{kv}$, with a resolution of $2.4 \mathrm{~A}^{\mathrm{o}}$ at the centralized instrumentation facility (SAIF), at IIT Bombay, Mumbai.

\subsection{SAED pattern analysis (selected area electron diffraction)}

SAED pattern analysis was performed to characterize the nature of the sample, as to whether the NP was amorphous (diffuse rings), crystalline (bright spots), or polynanocrystalline. Typically in a SAED pattern, a parallel beam interacts with the sample and produces the image. Phenomenally, the size of the area studied by SAED is a few hundred nanometers. These diffraction patterns are either simple spots corresponding to singlecrystal diffraction or rings corresponding to diffraction from multiple crystals with a variable orientation. SAED is commonly used for phase identification, determination of structural intergrowth and growth direction. Lattice parameters from SAED have an accuracy of approximately $5 \%$. On the other hand, due to multiple diffractions, forbidden reflections are often present [15].

\subsection{ZETA potential}

The stability of the NP synthesized was elucidated by analyzing the Zeta potential. Zeta potential is the measure of the charged species present at the NP surface that prevents it from aggregation and ensures the stability of the nanoformulation. The greater the positive or negative of the Zeta measure, the greater the stability of the NP [16].

\subsection{Fourier transform infrared spectroscopy analysis (FTIR)}

Fourier transform infrared spectroscopy, also known as FTIR analysis or FTIR spectroscopy, is an analytical technique used to identify organic, polymeric, and inorganic materials. The FTIR analysis method uses infrared light to scan the test samples and analyze their chemical properties. The synthesized nanoparticles were analyzed for the presence of functional groups that aid in the process of nanoparticle formation. The study was performed using the FTIR spectrophotometer (Perkin Elmer) at Bharathidasan University, Trichy.

\subsection{Phytochemical analysis of the green extracts}

The plant extract was tested for various phytochemicals such as terpenoids, flavonoids, saponins, tannins, phenols, coumarins, and triterpenoids, and the results were recorded. These phytochemicals served as reducing and stabilizing agents for the plant-mediated synthesis of nanoparticles.

\subsection{In vitro cytotoxicity of the AuNPs}

VERO cell line was used to determine the cytotoxicity of the synthesized AuNPs. The cell line was procured from the translational research platform for veterinary biologicals (TRPVB) TANUVAS, Chennai. About $1 \times 10^{4}$ cells (10,000 total cells) were added to each well of a 96-well tissue culture plate and incubated overnight. To this, different concentrations of AuNPs starting from 1.3, 0.65, $0.325,0.1625,0.8125,0.040625,0.020313,0.010156$, 0.005078 , and $0.002539 \mu \mathrm{g} / \mathrm{ml}$ were added and incubated 

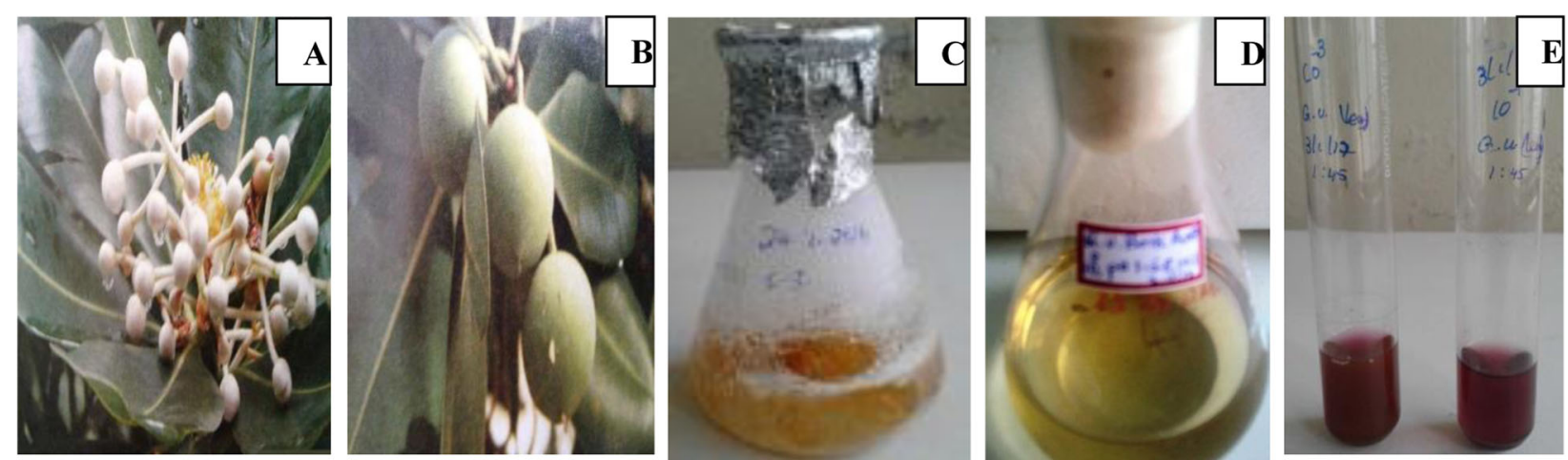

Fig. 1 a, b, c, d, e: leaves, fruits of Calophyllum inophyllum, extracts stored at $4^{\circ}$, Chloroauric acid solution, biosynthesized AuNPs

for $24 \mathrm{~h}$ at $37{ }^{\circ} \mathrm{C}$ in a $\mathrm{CO}_{2}$ incubator. Following this, 10 $\mu \mathrm{l}(5 \mathrm{mg} / \mathrm{ml})$ of MTT was added to each well and incubated for $3 \mathrm{~h}$ for the formation of formazan crystals. One hundred microliters of DMSO was added to dissolve the formazan crystals and incubated for an hour. The absorbance was read at $540 \mathrm{~nm}$ with a reference filter of $620 \mathrm{~nm}$. Percentage cytotoxicity was calculated using the formula: $100-$ (OD of treated cells/OD of control) $\times 100[17]$.

\subsection{Screening of AuNPs for antiviral activity against HIV-}

\section{1}

TZM-bl cells were plated in a 96-well format at a concentration of $1 \times 10^{4}$ cells/well and incubated at $37^{\circ} \mathrm{C}$ in a $5 \% \mathrm{CO}_{2}$ incubator for $24 \mathrm{~h}$ before infection. Virus stock at 0.005 MOI was pre-incubated with different dilutions of the nanocompounds (tenfold dilutions starting from $1 \times 10^{5} \mathrm{ng} / \mathrm{ml}$ to $1 \times 10^{-2} \mathrm{ng} / \mathrm{ml}$ ) for $2 \mathrm{~h}$ at $37^{\circ} \mathrm{C}$ before infecting the TZM-bl cells. At 40 to $48 \mathrm{~h}$ post infection, cells were lysed with $1 \mathrm{X}$ passive lysis buffer and luciferase expression was measured as relative light units using the Bright-Glo luciferase assay system. $\mathrm{IC}_{50}$ value was calculated using the Graph pad prism5 software.

\section{Results}

The plants and their parts used for the synthesis of nanocompounds (Fig. 1).

The gold nanoparticles were biosynthesized through reduction of higher metallic solution of Chloroauric acid with the fruit and leaf extracts of the plant Calophyllum inophyllum. The bioreduction was completed in less

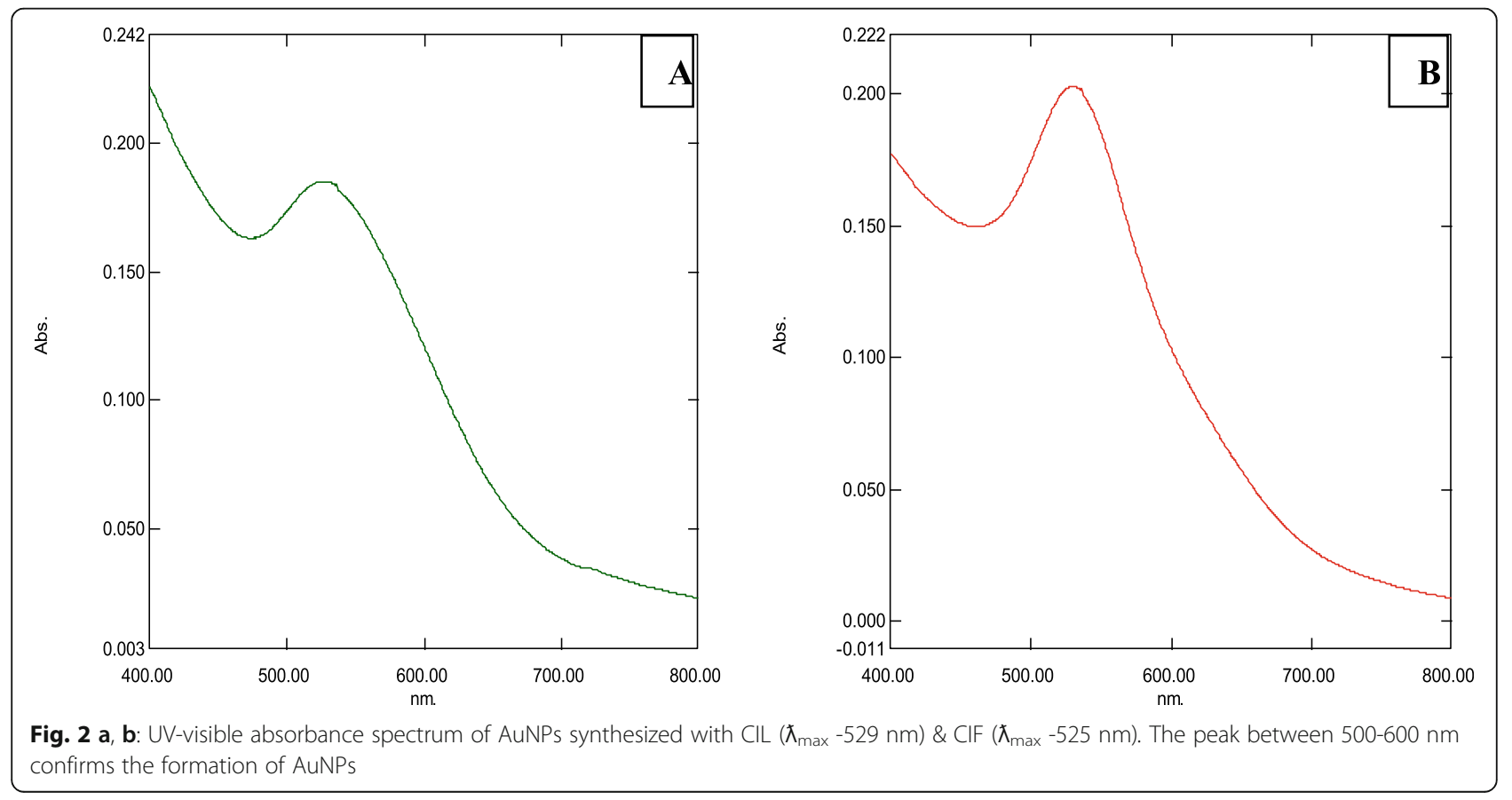



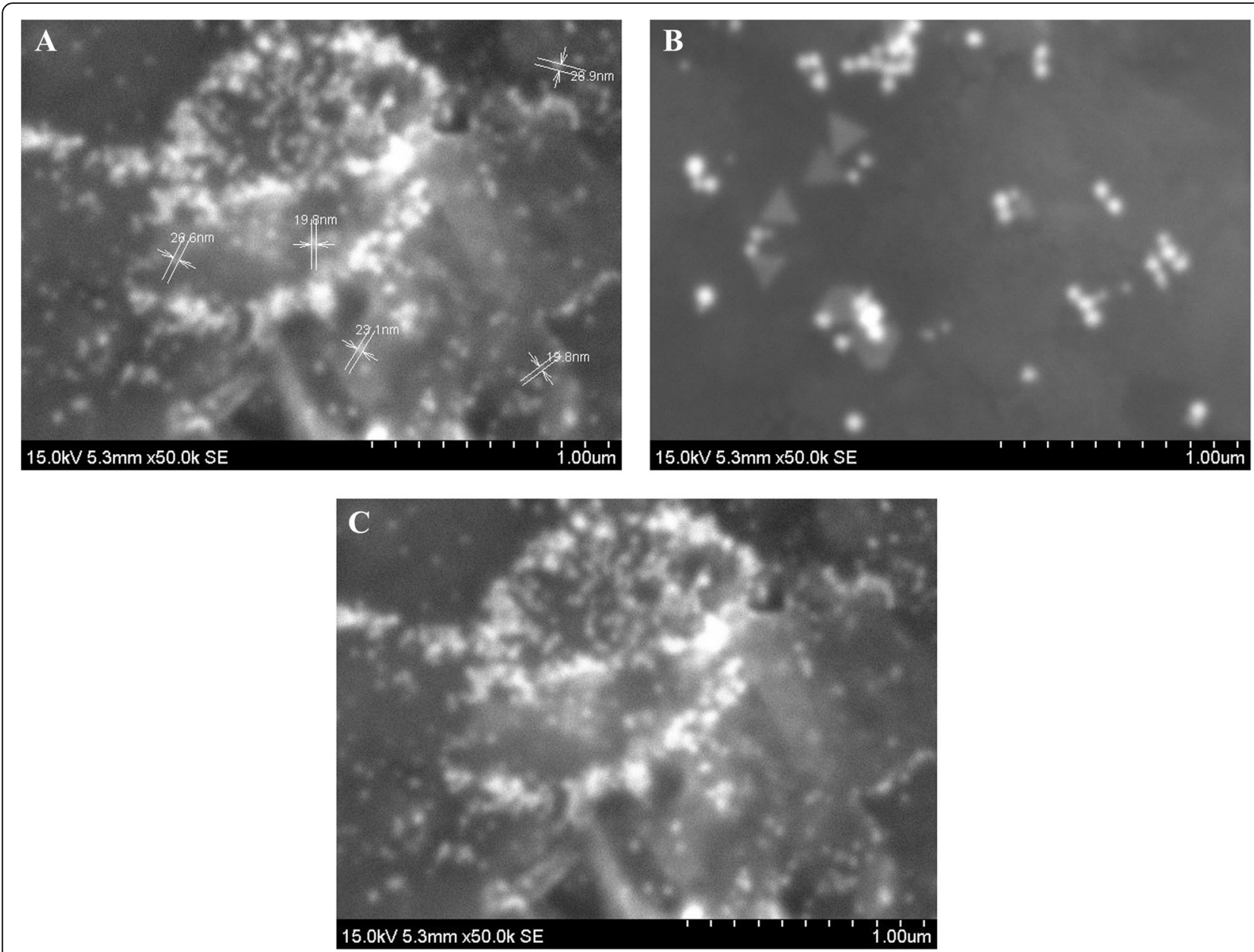

Fig. 3 a, b, c SEM micrographs of AuNPS

than an hour at room temperature. The green synthesized AuNPs were deep wine red in color.

\subsection{Characterization of nanoparticles using UV-visible spectrophotometer}

The UV absorption peak corresponds to the wavelength at which the optical absorption spectra of the metal nanoparticles are dominated by surface plasmon resonances (SPR). The absorption peak shifts to longer wavelengths with increasing particle size. The position and shape of the plasmon absorption spectrum of the gold nanoparticles are strongly dependent on the particle size, dielectric medium, and surface-adsorbed species. The number of SPR peaks increases as the symmetry of the nanoparticles decreases. Thus, spherical, disk-shaped, and triangular nanoparticles of gold show one, two, and more peaks respectively. Similar results have been reported by (Lal and Nayak, (2012) [18] (Fig. 2).

Similar results have been reported for nanoparticles synthesized by Jae Yong Song et al. [19].

\subsection{SEM (scanning electron microscopy)}

The size of the NPs was $12 \mathrm{~nm}$ upwards, on an average about $20 \mathrm{~nm}$, a commendable nano dimension achieved through plant-mediated synthesis. The NPs were spherical in morphology and evenly distributed. The significance of the size of the nanoparticles has also been stated by Jayanth and Vinod [20] (Fig. 3).

\subsection{EDAX-elemental analysis}

The EDAX elemental analysis of the synthesized gold nanoparticles was performed through the EDAX analysis on the SEM. This technique indicated the composition of various elements and relative concentrations of the elements present in the sample. Over the complete

Table 1 EDAX analysis of the nanoparticles

\begin{tabular}{lll}
\hline Element & Weight\% & Atomic\% \\
\hline O K & 32.70 & 85.67 \\
Au M & 67.30 & 14.33 \\
Total & 100.0 & 100.0 \\
\hline
\end{tabular}




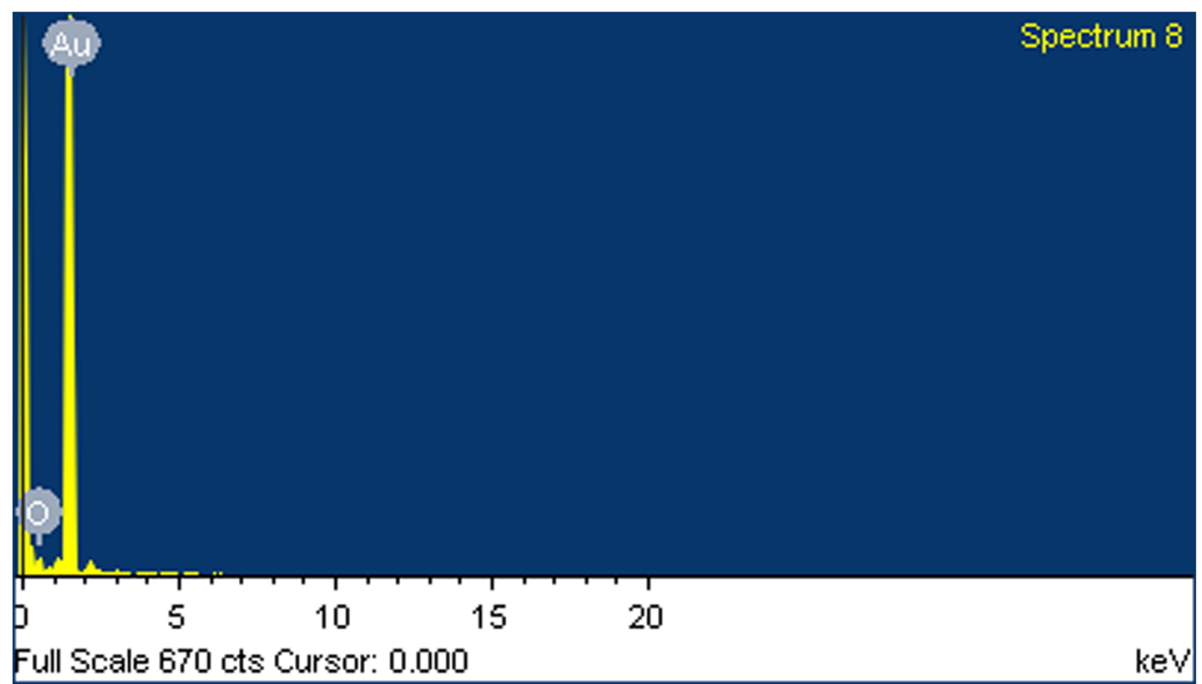

Fig. 4 EDAX analysis of the nanoparticles

scanning spectrum, throughout the range of binding energies, no obvious peak corresponding to any impurity was detected (Table 1 and Fig. 4).

The list of compounds present in the sample was given in the tables and the graph. The results implied that the synthesized nanomaterials consist of purely gold nanoparticles. Similar method of elemental analysis for gold nanoparticles has been reported by Jong, W. H. D., et al. [21].

\subsection{ZETA potential}

The stability of the synthesized NPs was measured through Zeta potential analysis. The Zeta potential analyzes the associated charges present on the surface of the NPs. This charge aids in the higher stability of the NM. It helps the particles to stay monodispersed and prevents agglomeration. Zeta measures exist in polar ranges, either toward positivity or negativity. Both of these ranges assure high stability of the NPs. The Zeta potential measurement also gives a projection of the stability of the synthesized colloidal suspensions [22]. In general, when the Zeta potential value is $>30 \mathrm{mV}$, there are less chances for agglomeration of the particles due to the electrostatic force between the particles (Bhumkar et al., [23]). Our results

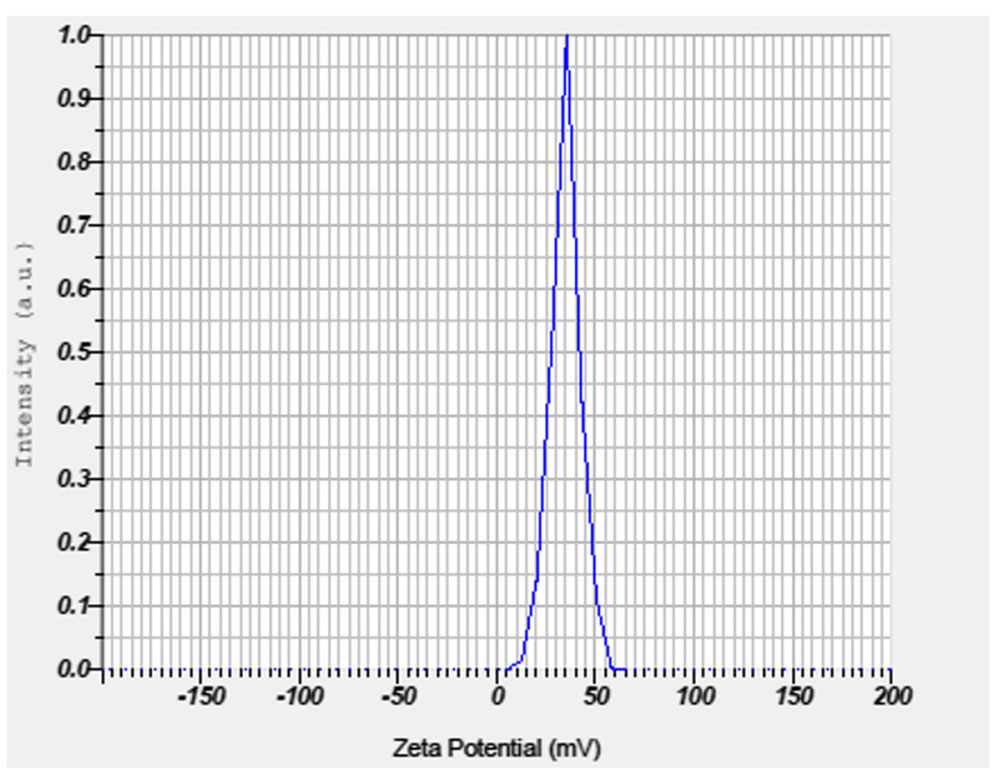

Fig. 5 Zeta potential analysis. CIL AuNPs_Zeta potential (mean): $-36.8 \mathrm{mV}$. CIF AuNPs_Zeta potential (mean): $-34.4 \mathrm{mV}$ 

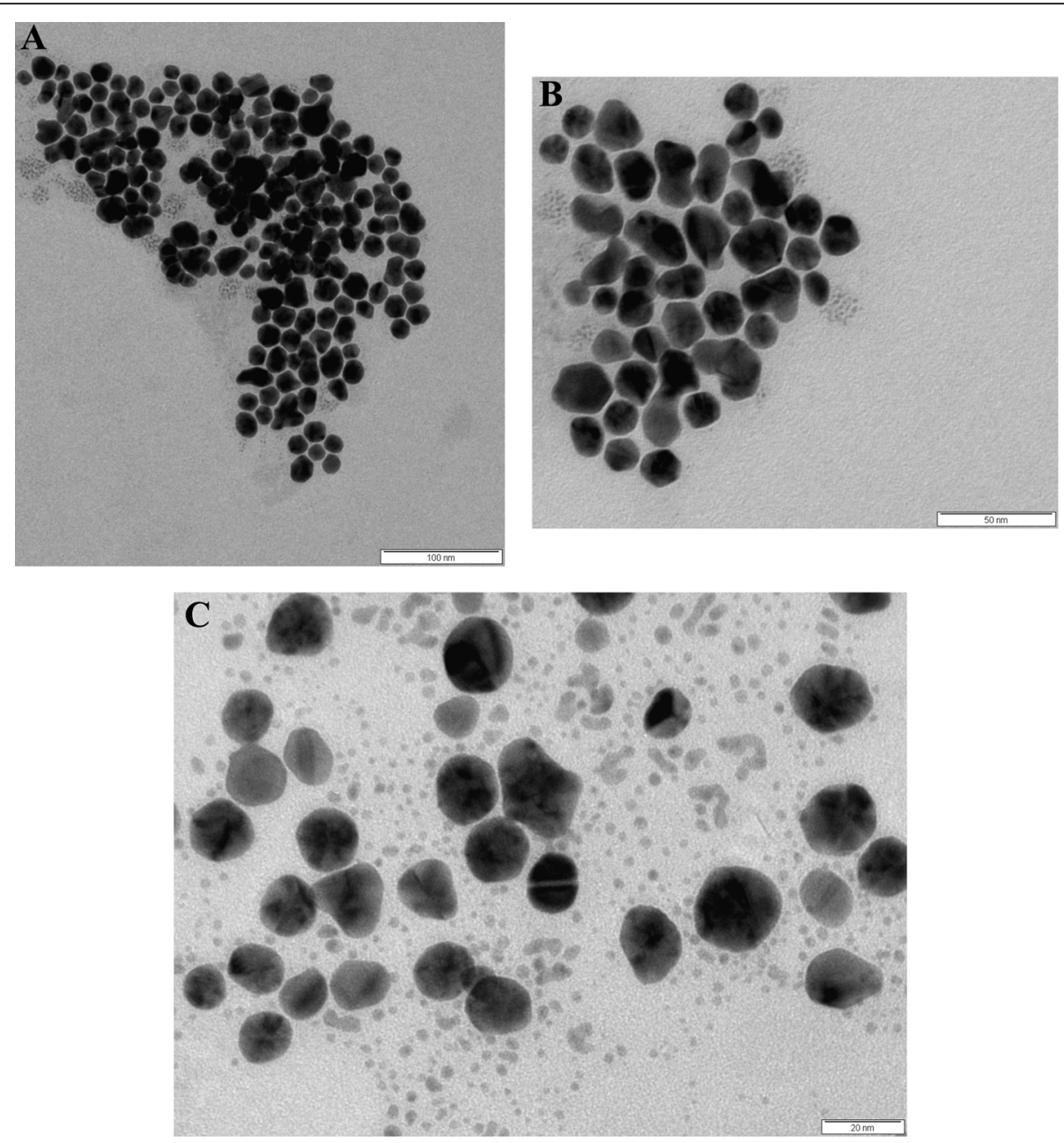

Fig. $\mathbf{6}$ a, b, c: TEM micrographs of AuNPs

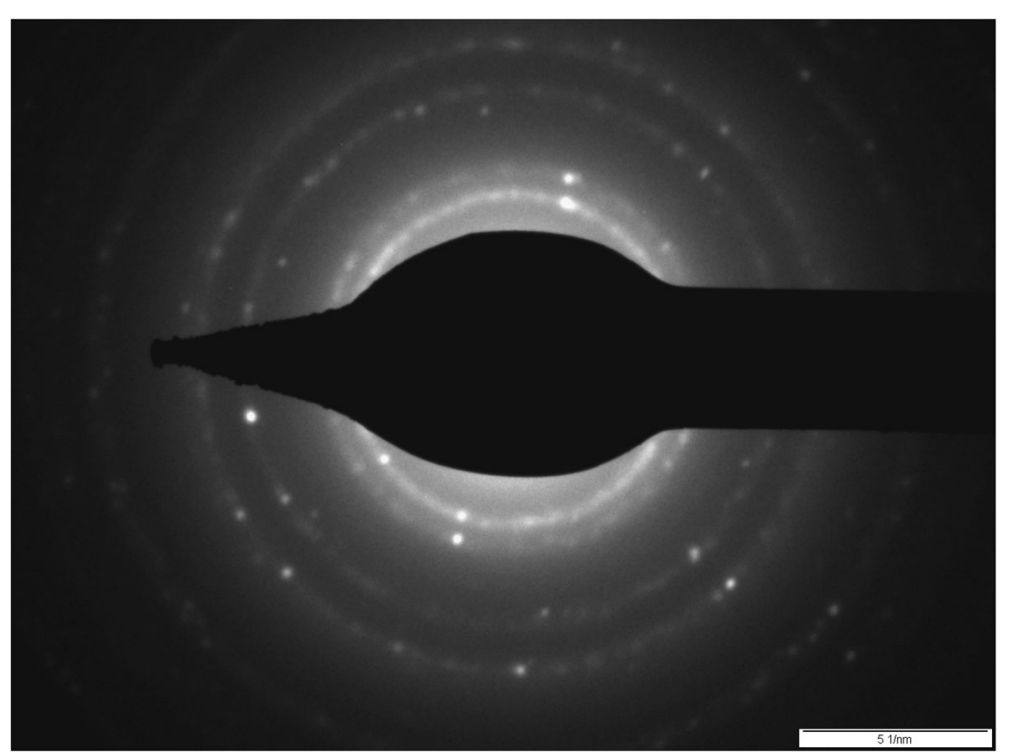

Fig. 7 SAED pattern of the AuNPS 
Table 2 Phyto chemicals present in the plant extract

\begin{tabular}{llll}
\hline S. no. & Compounds & C. inophyllum leaves & C.inophyllum fruit \\
\hline 1. & Coumarins & + & + \\
2. & Saponins & - & - \\
3. & Flavanoids & + & + \\
4. & Terpenoids & + & + \\
5. & Triterpenoids & + & + \\
6. & Carbohydrates & + & + \\
7. & Phenols & Brown color & Green color \\
8. & Tannins & + & Brownish green color \\
9. & Alkaloids & + & + \\
10. & Proteins & + & + \\
\hline
\end{tabular}

The number of signs indicates the intensity of results observed

$+=$ presence of the compound

$=$ absence of the compound

were in concordance to that reported by Bhumkar et al. [23] (Fig. 5).

\subsection{TEM (transmission electron microscopy)}

The transmission electron microscopic images obtained were in concordance with the SEM imaging reports. The synthesized AuNPs were spherical in morphology and the size ranged between $4 \mathrm{~nm}$ and $15 \mathrm{~nm}$ (Fig. 6).

\subsection{SAED pattern (selected area electron diffraction)}

SAED (selected area electron diffraction) pattern is used to check if the sample is amorphous (diffuse rings), crystalline (bright spots), or poly nanocrystalline. The images obtained showed the presence of bright spots, indicating the crystalline nature of the NPs (Fig. 7).

\subsection{Phytochemical analysis of the green extracts}

The leaf and fruit extract of the plant were screened for constituent compounds and secondary metabolites like coumarins, saponins, flavanoids, terpenoids, triterpenoids, carbohydrates, phenols, tannins, proteins, and alkaloids. The observed results are listed in Table 2 .

The FT-IR spectrum of the organic compounds corresponds to two regions, the functional group region (4000-1500 $\mathrm{cm}^{-1}$ ) and the finger print region (1500-400 $\mathrm{cm}^{-1}$ ). The peaks in the functional group region are used to identify the specific functional groups of the compound under study. Similar results have been reported by Kulanthaivel (2011) [24] (Fig. 8 and Table 3).

\subsection{In vitro cytotoxicity in VERO cell line}

The in vitro cytotoxicity of the AuNPs was tested in an epithelial cell lineage, the VERO cell line. Cytotoxicity was determined for varying concentrations of the nanocompounds. The results showed that the biosynthesized AuNPs exhibited very minimal cytotoxicity at all the evaluated concentrations (Fig. 9).

Cytotoxicity was ascertained by determining the percentage of viable cells after treatment with the AuNPs using the colorimetric MTT assay. The graph represents the \% cell viability upon treatment with varying concentrations of CIL AuNPs and CIF AuNPs. Minimum cell viability recorded was $80 \%$ at all concentrations AuNPs tested.

3.9 Screening of the nanocompounds for anti-HIV activity We tested the anti-viral activity of the nanoparticles against a laboratory adapted HIV-1 isolate, NL4-3 virus,

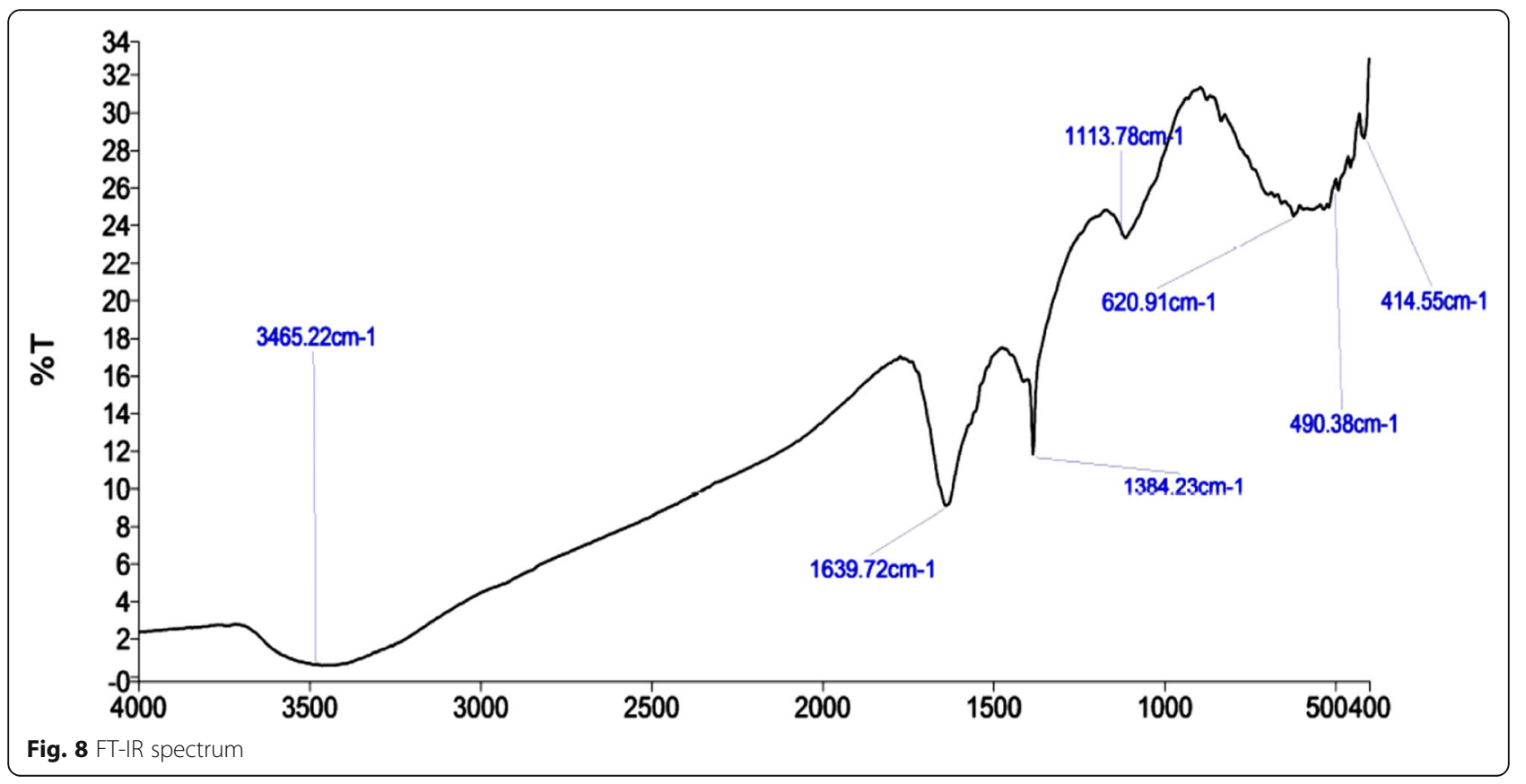


Table 3 FT—IR analysis (Fourier-transform infrared spectroscopy)

\begin{tabular}{lll}
\hline $\begin{array}{l}\text { S. } \\
\text { no. }\end{array}$ & $\begin{array}{l}\text { Wave number (absorptions) } \\
\left(\mathrm{cm}^{-1}\right)\end{array}$ & Functional groups \\
\hline 1. & 414.55 & \\
2. & 490.38 & \\
3. & 620.91 & $=(-\mathrm{C}-\mathrm{H})$ alkane \\
4. & 1113.78 & $(\mathrm{C}-\mathrm{O})$ alcohol, (C-O) Ester \\
5. & 1384.23 & $(-\mathrm{C}-\mathrm{H})$ alkane \\
6. & 1639.72 & $(\mathrm{C}=\mathrm{C})$ Alkene \\
7. & 3465.22 & (N-H) Amine, (O-H) alcohol \\
\hline
\end{tabular}

in a single-round-infection assay at various concentrations starting from $1.28 \times 10^{3} \mathrm{ng} / \mathrm{ml}$ and going down to $1.28 \times 10^{-4} \mathrm{ng} / \mathrm{ml}$ in tenfold serial dilutions. The percentage inhibition at each concentration was measured and plotted in the form of a graph (Fig. 8) in order to determine the $\mathrm{EC}_{50}$ value (Fig. 10).

The CIF NP gave $>90 \%$ inhibition at $1.28 \times 10^{3}$ to 12.8 $\mathrm{ng} / \mathrm{ml}$ concentration (Fig. 11).

The $\mathrm{EC}_{50}$ value for the CIF and CIL NPs against NL43 virus was found to be 0.1 and $0.08 \mathrm{ng} / \mathrm{ml}$ respectively.

\section{Discussion}

In the recent years, the green synthesis method employing plant extracts has gained more attention. Silver and gold nanoparticles were fabricated using the novel sundried biomass of Cinnammum camphora leaf. The nanoparticles were triangular or spherical in morphology and size was ranging from 55 to $80 \mathrm{~nm}$ [25]. In this present study, the nanoparticle of much smaller size (12$20 \mathrm{~nm})$ has been achieved. The efficiency of the nanoparticle is proportional to its dimension, smaller the size of the particle greater its efficiency.
One of the major problems with respect to synthesized nanomaterials is the aggregation of the nanoparticles. When the nanomaterials are highly stable, it prevents the formation of aggregates. The two major factors that determine the stability of nanoparticles are surface charge and ligand structure. Some stabilizers or capping agents such as surfactants, cyclodextrin, and thiol compounds are used to overcome the problem of aggregation and improve their stability. It has been demonstrated that AuNPs modified with PEG-SH were very stable without aggregation but AuNPs modified with other thiol compounds showed poor stability [26]. Whereas the biosynthesized AuNPs are found to be highly stable in aqueous solution without any stabilizers or capping agents for over a period of more than 24 months. Thus, a stable biocompatible nanoparticle is achieved which can be used for biological applications.

Various compounds isolated from Calophyllum were found to inhibit HIV-1 reverse transcriptase. Calophyllolide was the first isolated compound with anti HIV activity [27]. Calophyllum inophyllum shows anti-HIV activity by inhibiting virus replication and functional enzymes [28]. The organic extract of dried leaves and twigs of $C$. inophyllum have demonstrated activity against HIV RT. The inophyllum B showed anti-HIV activity with an $\mathrm{IC}_{50}$ value of 1.4 per Molar and was cytotoxic toward the host cells at 55 per Molar. The inophyllums act as potential inhibitors of HIV-1 reverse transcriptase and exhibits anti-HIV-1 activity in cell culture [29]. These studies were based on the crude extracts of C.inophyllum whereas in this current study, these extracts were developed into novel gold nanoformulations. And the HIV-1 inhibition was reported in a much lesser concentration than the crude extracts.

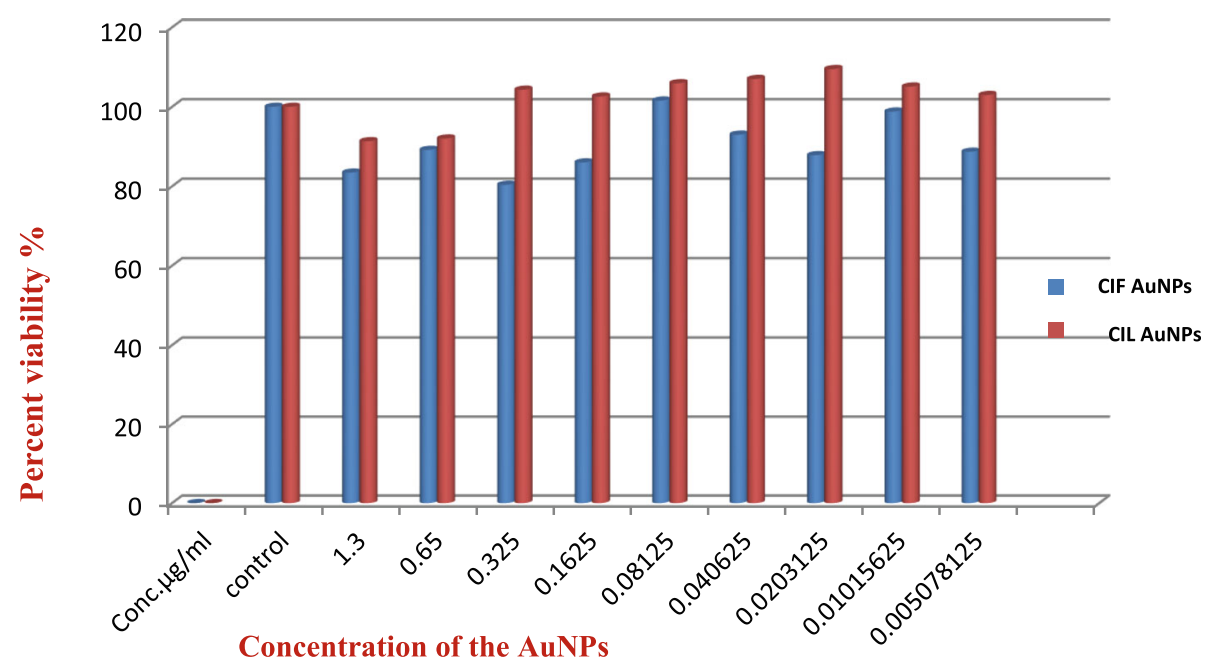

Fig. 9 Percent viability in treated VERO cell line 


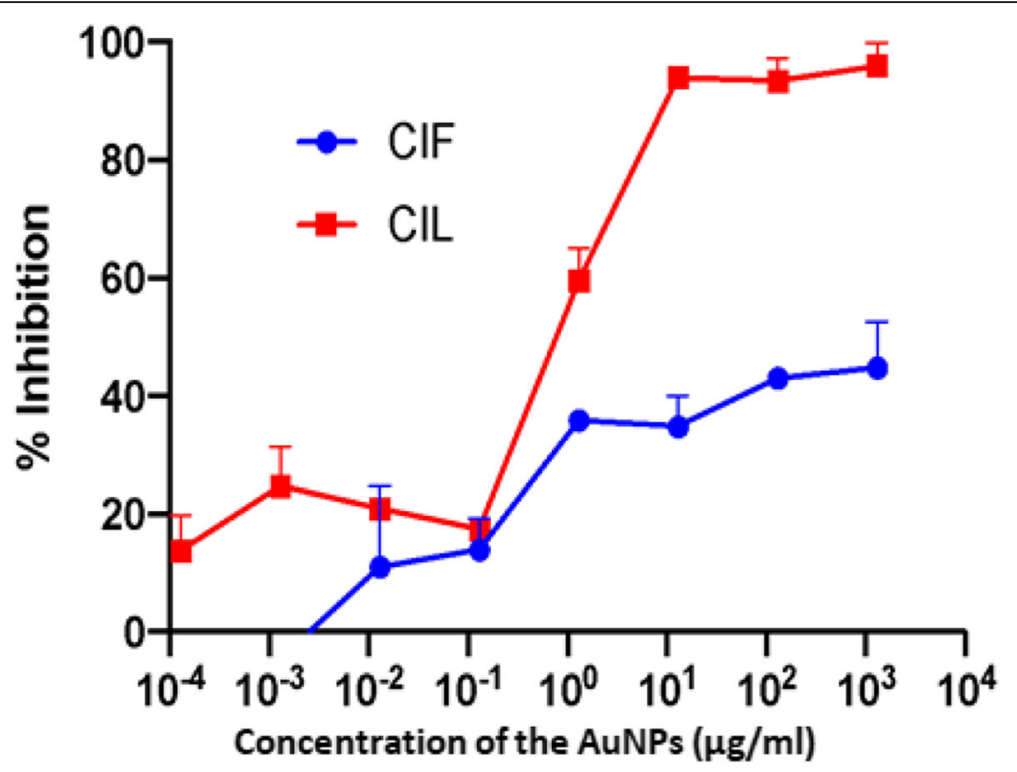

Fig. $10 \mathrm{TZM}$-bl cell lines $\mathrm{EC}_{50}$ concentration graph of the tested NPS

There are various reports on natural products possessing anti-HIV-1 property and acting at different stages of the HIV life cycle, namely, entry, integration and maturation. The anti-HIV-1 activity of one such species, Thymus, has been widely studied. Two species, namely, Th. quinquecostatus Celakovsky and Th. serpyllum L. were demonstrated to possess anti-reverse transcriptase activity. The root extract of other Thymus species and subspecies were also found to possess anti-RT activity. However, the anti-viral activity of the root extract was observed at the concentrations between 200 and $500 \mu \mathrm{g} /$ $\mathrm{ml}$. The extract of Th. Daenensis, subspecies daenensis, inhibited HIV-1 replication with an $\mathrm{EC}_{50}$ value of $300 \mu \mathrm{g} / \mathrm{ml}[30,31]$.

A number of studies have reported on the anti-HIV activity of plants such as Ocimum sauve, Ocimum sanctum, and Ocimum gratissimum, and their use on HIV/AIDS patients to manage AIDS-related illnesses. The in vitro anti-HIV activity of $O$. sanctum and $O$. gratissimum has been demonstrated earlier and its mechanism of action has been identified. Ocimum sanctum extract inhibits HIV-1 RT with an $\mathrm{IC}_{50}$ value of $72.22 \pm 6.04 \mu \mathrm{g} / \mathrm{mL}$ [30].

a

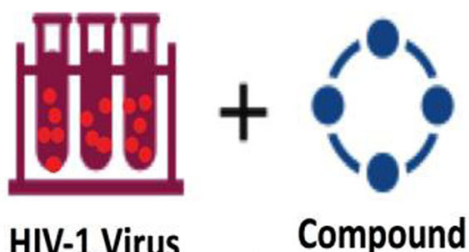

HIV-1 Virus Compound

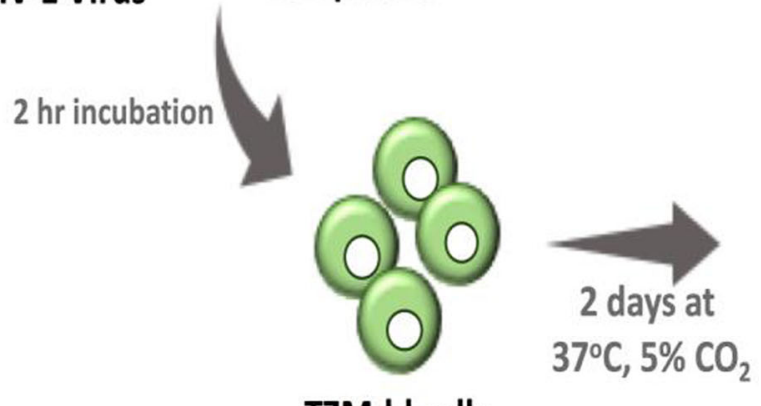

TZM-bl cells

Luciferase

Analysis

Fig. 11 Diagrammatic representation of the assay 
Since the $\mathrm{EC}_{50}$ values for most plant-based compounds were found to be very high, in the present study, we developed novel nanoformulations using the plant extract with the goal of increasing its anti-HIV property. The $\mathrm{IC}_{50}$ value of a drug is the effective concentration of the drug in tissue culture at which half of the infectious virus is inhibited from infection. This is determined by infecting the cells in culture with equal amount of infectious virus particle, after treating the cells at different concentrations of drug under study.

In general, gold nanoparticles provide non-toxic routes to drug and gene delivery application. Gold nanoparticles are capable of delivering large biomolecules (peptides, proteins, or nucleic acids like DNA or RNA). The gold nanoparticle protected by a thin layer of fluorinated amphiphilic thiols has been described. It is an example of water soluble gold nanoparticles protected by polymer layer [32]. The in vitro cytotoxicity results show that the minimum cell viability recorded was $80 \%$ at all concentrations of AuNPs tested. On this context, the biosynthesized AuNPs can be further used as drug carriers for HIV drugs. Additionally, since the AuNPs possess anti HIV activity as well, it can act in a combinatorial manner along with the drug, thereby enhancing the therapeutic index of the drug.

\section{Conclusion}

HIV/AIDS is indeed a major global issue. Even though it is treated with ART, there is always a constant urge for new alternatives, because of the numerous side effects associated with long term usage of these drugs and the emergence of drug resistance. We developed a nanoparticle using extracts of Calophyllum inophyllum leaf (CIL) and Calophyllum inophyllum fruit (CIF) based on its unique medicinal value. The initial confirmation of the nanoparticles was done using UV-visible spectrophotometry, which showed the characteristic peak for the nanocompound. Further, the imaging of the nanoparticles was carried out using SEM (scanning electron microscope) and TEM (transmission electron microscope), which revealed the size and shape of the synthesized nanoparticles. The size of the NPs ranged from 12$30 \mathrm{~nm}$, with an average dimension of $15 \mathrm{~nm}$. The morphology was predominantly spherical forming nanospheres; few nano triangles were also observed. The nanoparticles were evenly distributed. In vitro testing revealed that the nanocompound is non-toxic to normal cell and as well possessed potent anti-HIV activity. A further extended study can be carried out in combination with current ART drugs for an efficient disease control.

\section{Abbreviations}

NPs: Nanoparticles; AuNPs: Gold nanoparticles; CIL: Calophyllum inophyllum leaf; CIF: Calophyllum inophyllum fruit; SEM: Scanning electron microscopy;
TEM: Transmission electron microscopy; EDAX: Energy dispersive X-ray analysis; SAED: Selected area electron diffraction

\section{Acknowledgements \\ NA.}

\section{Authors' contributions}

PI designed and directed the study and KP executed the research work from synthesis of NPs, its characterization, phytochemical analysis, in vitro cytotoxicity studies, and was the major contributor in writing the manuscript. MA carried out the in vitro HIV studies, LP revived the cell lines for the anti HIV study, LEH supervised the entire anti HIV study. All authors read and approved the final manuscript.

\section{Funding}

No funding was received.

Availability of data and materials

All data and material are available upon request.

Ethics approval and consent to participate NA.

Consent for publication

Not applicable.

\section{Competing interests}

No competing interests to declare.

\section{Author details}

${ }^{1}$ Post Graduate and Research Department of Biotechnology, Women's Christian College, College Road, Chennai, Tamilnadu 600006, India. ${ }^{2}$ Department of HIV/AIDS, National Institute for Research in Tuberculosis, Chetpet, Chennai 600031, India.

Received: 1 December 2020 Accepted: 10 February 2021

Published online: 08 April 2021

\section{References}

1. Nano werk, Nanotechnology's role in HIV AIDS treatment https://www.na nowerk.com/Nanotechnology_role_in_HIV_AIDS_treatment.php Accessed on 10 Nov 2020

2. Lisziewicz J, Tőke ER (2013) Nanomedicine applications towards the cure of HIV. NMJ 9:28-38

3. Lewinski N, Colvin V, Drezek R (2008) Cytotoxicity of nanoparticles. Small 4: 26-49

4. Nanocomposix, transmission electron microscopy analysis of nanoparticles, 2012, Accessed on 11 Nov 2020

5. Curley P, Liptrott NJ, Owen A (2018) Advances in nanomedicine drug delivery applications for HIV therapy. Fut Sci OA 4(1):1-6

6. Baert L, et al (2009) Development of a long-acting injectable formulation with nanoparticles of rilpivirine (TMC278) for HIV treatment. Eur J Pharm Biopharm 72(3):502-508

7. Farsani MS et al (2016) The effect of root, shoot and seed extracts of the Iranian Thymus L. (Family: Lamiaceae) species on HIV-1 replication and CD4 expression. Cell J (Yakhteh) 18:256-261

8. Bajpai P (2018) Paper and its properties. In: Biermann's Handbook of Pulp and Paper, pp 35-63

9. Kamala Priya MR, lyer PR (2014) Extracellular rapid biosynthesis of gold nanoparticles using various green extracts of plants. Int J Mol Biol Biochem 2:33-40

10. Kamala Priya MR, lyer PR (2015) Comparitive study on the characterisation of gold nanoparticles synthesized using various plant extracts. Int J Phytother 5:17-21

11. Kamala Priya MR, Iyer PR (2014) Studies on the various parameters underlying the synthesis of nanoparticles and the in-vitro stability of nanoparticles. Front Biotechnol 1:1-4

12. Hues SM, Lovejoy L (2008) Ultratrace impurity analysis of wafer surfaces. In: Handbook of silicon wafer cleaning technology, pp 619-657

13. M. Klementová, Electron diffraction - SAED, CBED, PED, (2009) http://www. xray.cz/xray/csca/kol2009/abst/klementova.htm Accessed on 16 Nov 2020 
14. Khlebtsov N, Dykman L (2011) Biodistribution and toxicity of engineered gold nanoparticles: a review of in vitro and in vivo studies. Chem Soc Rev 40:1647-1671

15. Tyo KM, Lasnik AB, Zhang L, et al (2020) Sustained-release Griffithsin nanoparticle-fiber composites against HIV-1 and HSV-2 infections. J Controlled Release 321: 84-99

16. Kamala Priya MR, lyer PR (2020) Anti proliferative effects on tumor cells of the synthesized gold nanoparticles against Hep2 liver cancer cell line. Egyp Liver J 10:1-12 Springer

17. Kamala Priya MR, lyer PR (2014) Anticancer studies of the synthesized gold nanoparticles against MCF 7 breast cancer cell lines. Appl Nanosci 5:443448

18. Lal SS, Nayak PL (2012) Green synthesis of gold nanoparticles using various extract of plants and spices. Int J Sci Innov Discov 3:1-11

19. Yong Song J, et al (2009) Biological synthesis of gold nanoparticles using Magnolia kobus and Diopyros kaki leaf extracts. Process Biochemistry 44: 1133-1138

20. Panyam J, Labhasetwar V (2003) Biodegradable nanoparticles for drug and gene delivery to cells and tissue. Adv Drug Deliv Rev 55(3):329-347

21. Jong WHD, Burger MC, Verheijen MA, Geertsma RE (2010) Detection of the presence of gold nanoparticles in organs by Transmission Electron Microscopy. Materials 3(9):4681-4694.

22. Bhumkar DR, Joshi HM, Sastry M, Pokharkar VB (2007) Chitosan reduced gold nanoparticles as novel carriers for transmucosal delivery of insulin. Pharm Res 24(8):1415-1426.

23. Annamalai A, Babu ST, Jose NA, Sudha D, Lyza CV (2011) Biosynthesis and characterization of silver and gold nanoparticles using aqueous leaf extracts of Phyllanthus amarus Schum. \& Thonn. World Appl Sci J 13:1833-1840

24. Kulanthaivel M (2011) Evaluation and FTIR qualitative analysis and of gel based hand wash using Camellia sinensis (greentea) and Myristica fragrans (nutmeg) formulation. Int J Pharmaceut Biol Arch 2(4):1202-1208

25. Global Information hub on Integrated medicine, 2016, Globinmed, Selangor. http://www.globinmed.com/index.php?option=com_content\&view= article\&id=106100: calophyllum-inophyllum-I-106100\&catid=286\&ltemid=357 Accessed on 14 Nov 2020

26. Ghosh P, Han G, De M, Kim KC, Rotello MV (2008) Gold nanoparticles in delivery applications. Adv Drug Deliv Rev 60:1307-1315

27. Laure F, Raharivelomanana P, Butaud J-F, Bianchini J-P, Gaydou EM (2008) Screening of anti-HIV-1 inophyllums by HPLC-DAD of Calophyllum inophyllum leaf extracts from French Polynesia Islands. Anal Chim Acta 624(1):147-153

28. Govindappa M et al (2015) In vitro anti-HIV activity of partially purified coumarin(s) isolated from fungal endophyte, Alternaria species of Calophyllum inophyllum. Pharmacol Pharm 6:321-328

29. Patil AD, Freyer AJ, Eggleston DS, Haltiwanger RC, Bean MF, Taylor PB, Bartus HR (1993) The inophyllums, novel inhibitors of HIV-1 reverse transcriptase isolated from the Malaysian tree, Calophyllum inophyllum Linn. J Med Chem 36:4131-4138

30. Senapathi J, Bommakanti A, Mallepalli S, Mukhopadhyay S, Kondapi AK (2020) Sulfonate modified Lactoferrin nanoparticles as drug carriers with dual activity against HIV-1. Colloids Surf B Biointerfaces 191(110979):1-15

31. Kapewangolo et al (2017) Anti-HIV activity of Ocimum labiatum extract and isolated pheophytin-a. Molecules 22:1-12

32. Huang J, Li Q, Sun D, Lu Y, Su Y, Yang X, Chen C (2007) Biosynthesis of silver and gold nanoparticles by novel sundried Cinnamomum camphora leaf. Nanotechnology 18:105104

\section{Publisher's Note}

Springer Nature remains neutral with regard to jurisdictional claims in published maps and institutional affiliations.

\section{Submit your manuscript to a SpringerOpen ${ }^{\oplus}$ journal and benefit from:}

- Convenient online submission

Rigorous peer review

- Open access: articles freely available online

- High visibility within the field

- Retaining the copyright to your article

Submit your next manuscript at $\boldsymbol{\nabla}$ springeropen.com 